\title{
Occupational Therapy
}

BY NANCY ROSS,

\section{Occupational Therapist, Cambs. Mental Hospital.}

In spite of the prominence recently given to Occupational Therapy in the daily papers as well as in more specialised quarters, but little is generally known about it.

Some of its branches are almost completely ignored, as for instance, its value in orthopædic cases, where it can be utilised as an adjunct to massage and formal exercise, in restoring movement to disused muscles or in correcting contractions or other disablements. Again it is of the greatest service in neuroses and in functional nervous diseases, and, finally there is its use in Mental Hospitals, which is the subject dealt with here.

The therapeutic value of occupation was known to the ancient Greeks, by whom it was employed for the alleviation of mental disorders at certain shrines, where the patients were treated by medicinal baths, soothing music, and light work of an amusing nature. In the general stagnation of medical science that later set in, the art of occupational therapy was forgotten though at various times the value of work in mental ailments has been recognised. For the most part, however, the work was used for the good of the hospitalthat is to say it was indiscriminately applied to all patients, and only those tasks which aided in the economic running of the institution were encouraged. Since the War, knowledge of the effects of work and play has been put on a scientific basis and linked with the great advance in the science of psychology and the practice of psychiatry.

The development of Occupational Therapy in this country has, in recent years, been marked by a tendency to establish a system which is typically English in that it is a compromise between two methods. One, for the sake of clearness, we will distinguish as the American system, and the other, since it is exemplified at the Provincial Hospital at Sant Poort, near Haarlem, we will describe as the Dutch method.

The American method is to employ a varying number of fully trained aids or specialists, each having their workshops, to which the patients are sent, and only a small proportion of the work is done on the wards, and, except in the case of "Specials," or selected private patients, hardly any of it under the nurses.

The Dutch method is to employ the patients very largely on the wards and entirely under the charge of nurses, with a minimum of assistance from specialists in such crafts as weaving. The exponents of this method claim that the nurses naturally know the patients better than the specialist can, since they are with them all the time.*

*We read in a Report of the Devon Mental Hospital where this system is in force that during 1934, $75 \%$ of the patients were occupied daily and that the Hospital has become a " hive of industry." -ED. 
There is much to be said for either method, but there are also disadvantages from our point of view in each. The greatest difficulty in applying the American method is the expense-not only do special work shops have to be provided but the salaries of a sufficient staff of trained Therapists to cope with the numbers of patients in even our smaller mental hospitals amount to a very considerable sum. The difficulty in the Dutch method is that the nurse with her nursing examinations to pass and her practical work on the wards must have considerable difficulty in learning enough craft work to take entire charge of a class of patients, each of whom will present a separate problem.

For this reason there is a growing tendency in England to have one trained specialist-organiser and to give under her supervision, a sufficient training to the nurses to enable them to carry on the routine work of .classes in the wards or workshops, while the specialist stands ready to assist or suggest as necessary. The specialist works, of course, in close touch with the medical officer and, subject to his orders, selects the type of work for which individual patients are suited, and regulates the hours and the environment according to need.

There is an idea in some quarters that to be an Occupational Therapist, it is only necessary to know some handcraft such as leatherwork or to have passed through a school of art and perhaps have an interest in mental disease. Skill in arts and crafts is necessary, but to this should be added a thorough grounding in Psychology, normal and abnormal, a good knowledge of mental diseases and a large amount of common sense and tact, coupled with an ability to approach her patients in the right way. She should be able to teach elementary rhythmic exercises and games, and know something of dancing, music, the drama and community singing. Finally, she should have made a thorough study of the faculties required, the degree of physical skill involved and the standard of intelligence necessary for each craft or occupation.

A large percentage of the patients with whom she will have to deal will be of the "mass production" type of mind or will be so deteriorated by dementia that they will only be able to cope with the simplest processes. For the former, factory-like processes such as mat, brush, or shoe-making will be found suitable, and for the latter, rag picking, sand-papering or the like. It must, however, be borne in mind that even those who appear quite unemployable may be trained to do simple ward-mending or to knit cotton polishing clothes and so forth if the Therapist goes patiently and carefully to work. For these types rhythmic exercises and marching to music will be beneficial and they can also be taught to join in community singing especially if the airs chosen are those of familiar hymns.

A higher group can be set to more complicated tasks-simple dressmaking, carpentry, basketry. They should be trained in co-operation by means of team games, communal projects, charades, and group singing. Finally, there are those who have definitely creative minds, and who have been thwarted and frustrated in their endeavours to express themselves, and these may show but little mental deterioration. For them an outlet in arts and crafts, in music, 
drama, and dancing should be provided. If the prognosis is favourable, the patient will be allocated to the convalescent group where the occupations must be selected with an eye to the provision of suitable hobbies and pastimes for the outside world, while, for the others, the aim must be to aid the patient in adjusting himself or herself to institution life.

All these different groups should be arranged by the Occupation Therapist who must enlist the help of any nurses who show special aptitude or taste in one of these directions. The size of the classes must vary according to the type of patient. A certain number will be suitable for classes up to twenty-five but others will be better in smaller groups. A few will work best in comparative solitude. Some will need special attention while others will have to be trained to work in co-operation. Physical defects such as poor eyesight or shaky hands must be considered as the patient may require help in such operations as threading needles. The nurses who are to assist should understand one craft thoroughly and have a grounding in several others and it would also be advisable to give them a brief theoretical and practical training in the planning and selection of work and its application to the cases of various patients. Very close co-operation between the nurse and the Occupational Therapist will be necessary.

Whatever system is adopted the ultimate aim of the occupations should never be forgotten. It is, of course, the cure of the patient or failing that his better adjustment to the world around him. The benefit of the work to the hospital, or the sums received for the sale of articles should always be a minor consideration.

The re-adjustment, re-education, and the re-establishment of habits of right thinking should be emphasised. In the most retrograde types, training in self-respect, and cleanliness is indicated. Destructive patients should have their activities directed into constructive channels. Violence should be sublimated or soothed by vigorous work such as scrubbing or soothing work such as knitting. Noisy patients can be taught to relax. Anti-social types can be made to realise that the work they do evokes the admiration and the appreciation which society has, in their view, unjustly withheld from them. Hence the value of good design and colour as these will evoke spontaneous praise from visitors, apart from the satisfaction which the worker feels in his own work. Social emotions such as pity or affection, and respect for others can be aided by practical suggestions such as the knitting of a scarf for a chilly friend, or by the carrying out of some responsible duty on the ward or for the Therapist.

Co-operation and team work should be built upon until the patient finds that he or she takes a real pride in the care of the ward, the appearance of the garden, or in the production of a patients' concert, quite apart from his or her own individual effort. Many will halt at each step in this ladder towards complete cure, but it is safe to say that each one should be, at least, one rung higher than before the occupational organisation came in touch with him.

The number of crafts which may be used is enormous and they vary greatly in their value. The best all round appears to be hand weaving, as 
there are so many variations of it, ranging from simple raffia weaving on cards to the artistic and complicated crafts of tapestry and double weaving. It is a craft with a considerable rhythm which is highly desirable and $i_{i}$ is suitable for either sex. Its products are both useful and beautiful and incidentally saleable. Embroidery, especially that on counted threads, is good and helps to develop colour sense. Knitting is a good soothing craft but is apt to encourage day dreaming. Basketry and the cane seating of chairs, woodwork and toy-making are all useful especially for the men. Pottery and modelling are not of great use but wood carving might be desirable in some cases. Leather work is not of much use as the material is expensive and easily spoiled. Together with book-binding it is only suitable for a small percentage of higher grade patients. Articles for the hospital wards, such as cushions, curtains and rugs are welcome as a rule and the makers like to see them in use.

The use of machinery is a saving of time in factory processes but an indiscriminate employment of sewing machines, knitting machines, and so forth is not advisable. Many patients, before entering hospital, suffered from present day mechanisation and are consciously, or sub-consciously, in revolt against machine processes. A patient the other day said she had been making plain shirts by machine for twenty years and was so glad to make "something pretty by hand." In opposition to this, a few-but very few-subconsciously yearn for factory processes, as did a young man of the undergraduate intelligentsia type (outwardly) who, never having used his hands in work or hobby before, found the greatest satisfaction in mat making. Machinery has another drawback in that it encourages laziness, which is already too characteristic of the dementia praecox patient.

The golden rule is to study the individual, and so far as possible sublimate or satisfy their desires or subconscious yearnings. Interest is necessary and should be stimulated as much as possible, and there is room for a vast amount of observation and research into the effects of different work on different patients. It is clear that this is work for the specialist Occupational Therapist and that there is and will be a great need of trained workers of the right type.

The profession is in its infancy and though much good work is being done, much of it in isolation, it is plain that co-ordination, and higher standards of qualifications are much needed. With this end in view a few occupational therapists who already know each other are trying to form an association for those who have, either by long experience and ability, or by special training, qualified themselves to give a definite contribution. It is proposed to hold a general meeting in London in order to form such an association, and, in the meanwhile, those interested in the project, who have not yet received the circular letter on the subject, should write to Miss E. M. Macdonald, I9, Grove Way, Esher, Surrey, who is acting as Temporary Secretary. It should, however, be clearly understood that the association is not intended for craft workers but for those with definite training or practical working experience of some length as Occupational Officers in a hospital or institution. 